\title{
Arquitectura y urbanismo en español
}

"La calidad nunca es un accidente, siempre es el resultado de un esfuerzo de la inteligencia"

John Ruskin

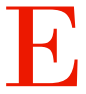

s evidente que la arquitectura y el urbanismo en el ámbito iberoamericano se encuentra en una fase de florecimiento, y los reconocimientos internacionales que se hacen a profesionales de América Latina y la Península Ibérica así lo indican. En el año 2016 el chileno Alejandro Aravena (1967) recibió el Premio Pritzker, y en 2017 fue concedido este mismo galardón a los arquitectos catalanes Rafael Aranda (1961), Carme Pigem (1962) y Ramón Vilalta (1960), del estudio RCR Arquitectes. E Premio Pritzker, concedido por la fundación Hyatt, es e reconocimiento internacional más prestigioso del mundo, y es por ello que se suele denominar "el Nobe de la arquitectura". Para nosotros es la prueba de que e ámbito hispanohablante está en franco progreso en todo lo referente a nuestras disciplinas. Si la buena arquitectura se está haciendo en países que comparten una lengua común, la comunicación científica en españo resulta en estos momentos de gran importancia.

Con la lingüística de nuestro lado, ESTOA pretende, con este nuevo número, participar en el vivo debate de la arquitectura que se gesta en los diversos, pero bien conexos, territorios iberoamericanos. Y lo cierto es que las revistas científicas de arquitectura y urbanismo no son muchas en la esfera hispanohablante, por lo que desde esta plataforma nos preocupamos particularmente por problemáticas latinoamericanas, y casos de estudio que precisan investigación y sobre todo soluciones. En este sentido, revistas científicas como ESTOA vienen a suplir una carencia secular, dando cobertura comunicacional a la arquitectura y a urbanismo de Iberoamérica, habida cuenta de que las revistas internacionales de impacto -en su mayoría anglosajonas- no suelen estar interesadas en publicar artículos sobre lo que sucede por nuestras latitudes a considerar que son objetos de estudio demasiado locales.

Si la arquitectura se premia y el urbanismo se desarrolla es el momento de fortalecer los canales de comunicación científica sobre nuestras disciplinas. A veces algo tan simple como una revista de investigación es el detonante para que emerja toda una corriente de pensamiento o una nueva área de estudio. Recordemos a la Revista de Occidente, fundada en 1923 por el filósofo Ortega y Gasset, que fue la plataforma para sus ideas raciovitalistas y para las contribuciones de filósofos tan relevantes como Bertrand Russell o Edmund Husserl. Recordemos también a la revista Annales, fundada en 1929 por Marc Bloch y Lucien Febvre, con la que se inició el enfoque historiográfico de la Escuela de los Annales, que tuvo una inmensa difusión en la investigación histórica en durante gran parte del S. XX.

Las mentes inquietas fundan revistas porque saben que van a dar alas a la ciencia; saben que la comunicación científica es esencial ya que las ideas necesitan ser escuchadas para participar en el debate internacional. Y es con este nuevo número de ESTOA que pretendemos, una vez más, intervenir con una presencia meritoria en ese debate de la ciencia hecha en español.

Ing. Fabián Cazar Almache fabian.cazar@ucuenca.edu.ec Ph.D. José Luis Crespo Fajardo luis.crespo@ucuenca.edu.ec Comité Editorial de ESTOA Cuenca, junio de 2018 